\title{
Cartilage and bone macromolecules in knee joint synovial fluid in rheumatoid arthritis: relation to development of knee or hip joint destruction
}

Bengt Månsson, Pierre Geborek, Tore Saxne

\begin{abstract}
Objective-To examine the hypothesis that aggrecan, cartilage oligomeric matrix protein (COMP), and bone sialoprotein (BSP) concentrations in synovial fluid could provide information on variations of progression of joint destruction in rheumatoid arthritis.

Methods-Aggrecan, COMP, and BSP were quantified by enzyme linked immunosorbent assays in longitudinally collected knee joint synovial fluid samples of patients rapidly developing destruction in knees or hips, the "destructive" group, $n=18$, and in patients slowly developing destruction, the "non-destructive" group, $\mathrm{n}=25$.
\end{abstract}

Results-The aggrecan concentrations decreased from initially high levels $(P<<$ 0.001), and the BSP concentrations increased $(P<<0.001)$ over time in the destructive group, whereas levels of both markers were low and did not change in the non-destructive group. The COMP levels did not change in any of the groups. The aggrecan concentrations were initially highest in the group developing destructions $(P<<0.001)$, whereas no difference between the groups was found regarding levels of COMP or BSP in the first sample.

Conclusions-A destructive group was characterised by higher initial aggrecan concentrations and rising BSP concentrations in synovial fluid with time. Quantification of cartilage and bone derived macromolecules contributes to the assessment of extent of tissue destruction and may help in the early identification of patients at risk of rapidly progressing destruction.

(Ann Rheum Dis 1997;56:91-96)

Department of Rheumatology, Lund University, Lund, Sweden

B Månsson

P Geborek

T Saxne

Correspondence to: Dr Tore Saxne,

Department of Rheumatology, Lund University Hospital, S-221 85, Lund, Sweden.

Accepted for publication 7 November 1996 degradation. ${ }^{1-5}$ However, it is well known that the extent and progression rate of tissue damage varies considerably among patients with rheumatoid arthritis. ${ }^{6}$ There is evidence that the intensity of local or generalised inflammation, as measured by conventional markers of inflammation, may correlate with future structural joint changes. ${ }^{7}$ However, a fair proportion of patients develop little radiographically visible structural damage despite a prolonged marked inflammatory response. ${ }^{89}$ Factors that may influence the process include the genetic background, which may modulate the susceptibility of different individuals to the negative influence of the inflammatory process. ${ }^{10}$ Thus it appears that inflammation and joint damage are not always closely connected, and levels of inflammatory markers are often not reliable correlates of tissue destruction. There is currently a lack of methods to detect early consequences of the inflammatory and destructive processes. At the time of radiographic changes the damage at the tissue level is already far advanced and radiography is therefore not suitable for detection of early tissue lesions.

During development of tissue damage in arthritis, matrix macromolecules or fragments thereof are released into the synovial fluid. By using specific immunoassays it has in recent years become possible to quantify and characterise several such tissue antigens in body fluids. ${ }^{11-15}$ Thus it is now possible to detect the development of tissue damage in arthritis also in the very early phases of the process.

Two cartilage macromolecules with potential for monitoring tissue involvement in arthritis are the large, aggregating proteoglycan (aggrecan) and a non-collagenous matrix protein, cartilage oligomeric matrix protein (COMP). ${ }^{16}$ In cross sectional studies we have shown that release of fragments containing epitopes in the chondroitin-sulphate-rich region of the aggrecan core protein varies according to degree of joint damage measured by radiography. The highest synovial fluid levels are found early, when no or little radiographic damage is apparent. ${ }^{1718}$ Similar, albeit smaller, changes have been found for COMP. ${ }^{19}$ Increased release of these markers in rheumatoid arthritis probably reflects increased tissue turnover with a tendency towards predominance of matrix degradation. Such changes could occur very early in progressive cartilage destruction, well before radiographic changes are visible, and might be predictive of more pronounced later tissue destruction. In support of this hypothesis we have found that high knee joint synovial fluid 
aggrecan concentrations predicted destruction of the knee joint 10 years later in a group of rheumatoid arthritis patients with long standing disease (median disease duration at inclusion 11 years). ${ }^{20}$

Bone sialoprotein (BSP) is a bone specific macromolecule, particularly enriched in the cartilage-bone interphase. ${ }^{1621}$ In a cross sectional study we have shown that synovial fluid levels of this protein are highest in rheumatoid arthritis patients with advanced structural changes as visualised radiographically. $^{22}$ In early stages the synovial fluid concentrations are low, and usually below serum concentrations. These findings indicate that the predominant subchondral bone involvement occurs in a phase of the disease when considerable cartilage damage is already present.

In the present study we have identified two patient groups with rheumatoid arthritis with markedly different progression of destruction of hip and knee joints, or both, where knee joint synovial fluid samples were available early in disease when no radiographic changes were detected, either in knees or in hips. Synovial fluid aggrecan, COMP, and BSP concentrations were monitored longitudinally to elucidate whether the two patient groups differed in their release of these tissue markers during the disease course, and whether the synovial fluid concentrations of any of these tissue derived macromolecules correlated with development of structural changes in hips or knees.

\section{Methods}

PATIENTS

The patient groups were identified by a computer search of a bank of synovial fluid and serum samples collected consecutively from patients in whom knee joint arthrocentesis had been performed because of synovitis requiring a therapeutic glucocorticoid injection. The primary inclusion criteria were a diagnosis of rheumatoid arthritis according to the criteria of the American College of Rheumatology ${ }^{23}$ and a disease duration at the first sample collection of less than six years. A further requirement for inclusion was normal knee and hip joint radiograms, that is, Larsen index 0-1, at the time of the first knee joint fluid aspiration. ${ }^{24}$

The primary outcome measure was knee or hip joint destruction requiring joint replacement; that is, one or more joint replacements in these joints classified the patient as having a "destructive arthritis". These patients all had radiographic changes corresponding to Larsen grade 4 or 5 (severe destruction) in the operated joint at surgery. Knee and hip joint radiographic examination was performed in patients who at follow up had a disease duration of more than seven years and had not been subjected to knee or hip joint replacement. The patients with normal radiographs (Larsen grade 0-1) at follow up were classified as having a "non-destructive arthritis". All radiograms were graded by the investigators before other analyses were performed.

SAMPLE COLLECTION AND IMMUNOASSAYS Synovial fluid samples were obtained between 10 am and $2 \mathrm{pm}$ after normal ambulatory activity and with at least 20 minutes of rest before sampling. The fluids were treated and stored as previously described. ${ }^{22}{ }^{25}$ Aggrecan, COMP, and BSP were quantified by enzyme linked immunosorbent assays using specific polyclonal antisera. ${ }^{1922} 25$ The aggrecan antiserum recognises epitopes in the core protein of the molecule. All samples from a given patient were assayed in one microtitre plate. Analyses were performed without knowledge of the clinical characteristics of the patients. The intra- and interassay variations of the assays were for aggrecan $6 \%$ and $8 \%$ respectively, and for COMP 5\% and $8 \%$ respectively. For BSP both intra-assay and interassay variations were $<10 \%$.

\section{STATISTICAL CALCULATIONS}

Comparisons of matrix protein levels between groups were calculated using the MannWhitney $U$ test (two tailed). The Wilcoxon matched pairs test (two tailed) was used for comparing levels within groups. The $\chi^{2}$ test was used for comparing the groups for differences in gender, Waaler-Rose titre, or treatment. Life table analysis was performed according to Kaplan-Meier. A P value of $<0.05$ was considered significant.

\section{Results}

PATIENTS

Figure 1 shows a flow chart of the patient selection procedure. Of the 69 patients initially identified as fulfilling the primary entry criteria, eight who had undergone replacement surgery were not included since it was not possible to ascertain that their joints were radiographically normal at the time of the first fluid sampling. Another 11 patients were deceased or had moved and were not available for follow up. Four patients who had not undergone any arthroplasty refused follow up radiographic examination.

Of the remaining patients, 18 had undergone joint replacements and were included in the destructive group. This included 16 hip replacements in 14 patients and four knee replacements. Twenty eight patients were examined radiographically at follow up. Twenty five of these had normal radiographs and were included in the non-destructive group. Three patients had intermediate changes (Larsen grade 2-3) and were not further analysed.

Table 1 shows some characteristics of the patient groups. The disease duration was slightly longer in the non-destructive group at the time of study entry; however, the overlap between the groups was marked. The number of available samples per patient, which equals the number of glucocorticoid injections received, was higher in the destructive group. 
Table 1 Some characteristics of the patient groups. Values are numbers or median (range)

\begin{tabular}{|c|c|c|c|}
\hline & Non-destructive group & Destructive group & $\begin{array}{l}\text { Difference } \\
(P \text { value })\end{array}$ \\
\hline No of patients (females/males) & $25(10 / 15)$ & $18(6 / 12)$ & NS \\
\hline Age at sample 1 (years) & $50.0(21.8$ to 75.2$)$ & $\begin{array}{l}52.0(20.2 \text { to } \\
72.4)\end{array}$ & NS \\
\hline Disease duration at sample 1 (years) & $1.5(0.5$ to 4.0$)$ & $1.0(0.2$ to 6.0$)$ & 0.05 \\
\hline $\begin{array}{l}\text { Disease duration at first joint surgery } \\
\text { (years) }\end{array}$ & - & $5.5(2.6$ to 9.2$)$ & - \\
\hline $\begin{array}{l}\text { Disease duration at radiographic follow } \\
\text { up (years) }\end{array}$ & $9.0(6.8$ to 13.4$)$ & - & - \\
\hline $\begin{array}{l}\text { Waaler-Rose titre } \\
\text { (positive/negative) }\end{array}$ & $21 / 4$ & $14 / 4$ & NS \\
\hline $\begin{array}{l}\text { Available samples/patient by aspiration } \\
\text { before administration of glucocorticoids }\end{array}$ & $2(1-7)$ & $4(1-11)$ & 0.02 \\
\hline NSAID treatment at sample 1 & 22 & 17 & NS \\
\hline SARD treatment at sample 1 & 6 & 4 & NS \\
\hline Oral glucocorticoid treatment at sample 1 & 2 & 1 & NS \\
\hline
\end{tabular}

NSAID, non-steroidal anti-inflammatory drug; SARD, slow acting antirheumatic drug.

This is also a measure of local symptoms of inflammation. In 15 patients (three in the destructive group, 12 in the non-destructive group) only one synovial fluid sample was available. There was no difference between the groups regarding treatment at the time of study

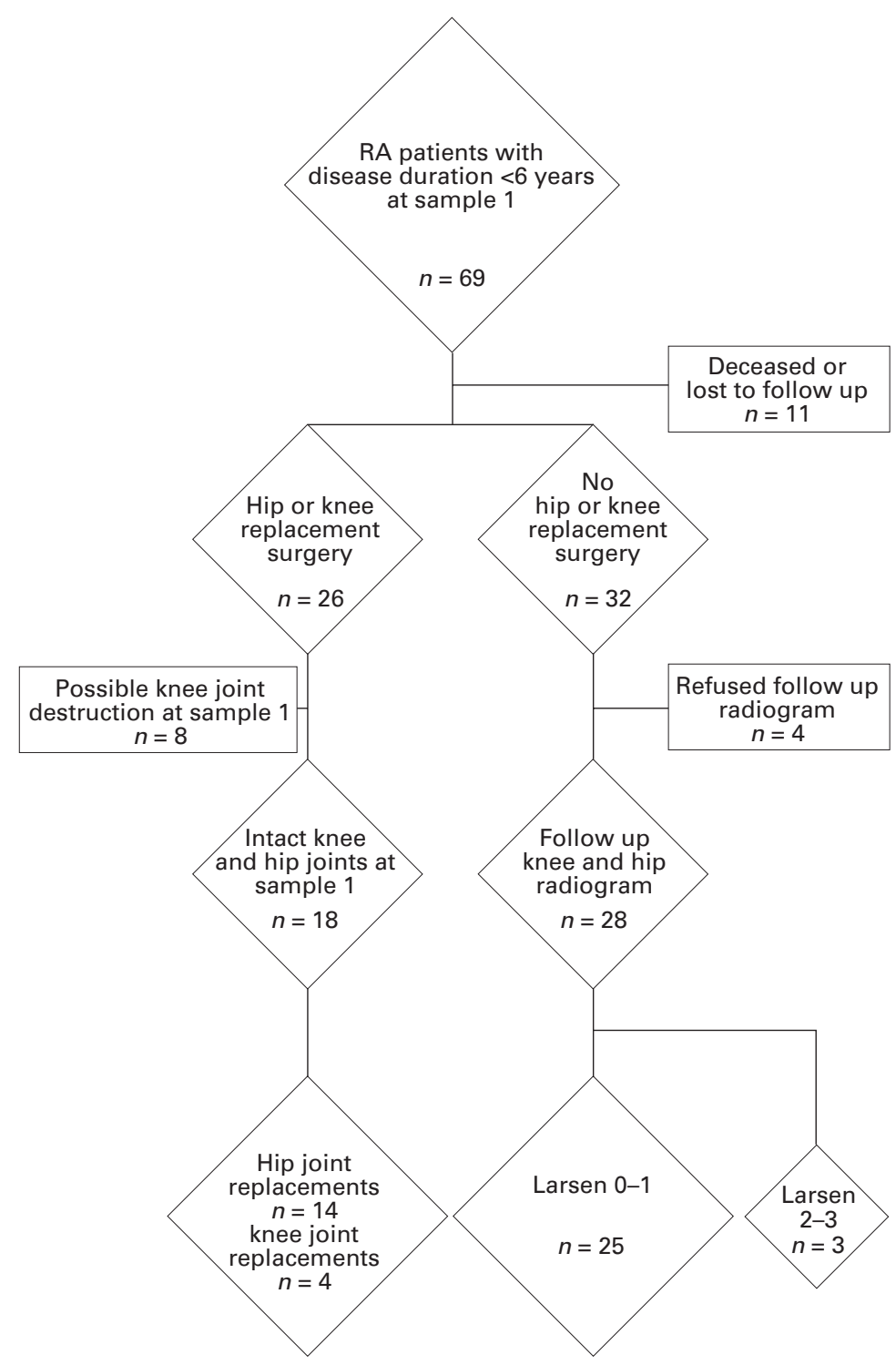

Figure 1 Flow chart of the patient selection procedure. For explanations see text. entry. No detailed comparison of the treatment regimens given during the whole study period was performed.

SYNOVIAL FLUID CONCENTRATIONS OF

AGGRECAN, COMP, AND BSP

Table 2 shows the synovial fluid concentrations of the tissue markers in the first available sample in the two patient groups (one knee per patient). The concentrations of aggrecan were highest in the destructive group, as was the aggrecan/COMP ratio. The aggrecan/COMP ratio was used to minimise the influence of varying amounts of obtainable synovial fluid. The COMP and BSP concentrations did not differ between the groups. Life table analysis relating the synovial fluid concentrations of aggrecan or the aggrecan/COMP ratio in the first sample of all 43 patients to the cumulative percentage of hip/knee joint replacements showed a significant correlation between levels of the synovial fluid variables and percentage of patients undergoing joint replacements $(\mathrm{P}<$ 0.006 for aggrecan, $\mathrm{P} \ll 0.001$ for the aggrecan/COMP ratio). Figure 2 shows the life table analysis for the aggrecan/COMP ratio.

In the longitudinal comparisons all available samples were included, that is, both knees from some patients were assessed, and monitored separately. The number of individuals and knee joints included for each variable is given in the figure legends.

The synovial fluid concentrations of aggrecan, which initially were highest in the group developing destructions, subsequently decreased as destruction progressed (fig 3). Consequently, the levels in the final sample differed significantly from the levels in the first sample $(P<<0.001)$. The values in the final samples did not differ from those in the non-destructive group. In the latter group the aggrecan concentrations did not change over time.

The COMP concentrations did not differ between the groups and did not change over time (fig 4).

The ratios between the synovial fluid aggrecan and COMP concentrations, shown in fig 5, were initially highest in the group developing destructions (table 2), and then decreased in a similar manner to the aggrecan concentrations in this group ( $\mathrm{P}<<0.001)$.

The samples available for longitudinal monitoring of BSP were fewer than for the other markers in the non-destructive group for technical reasons. The concentrations did not change over time in this patient group. In the destructive group increasing levels of BSP were seen during progression of joint destruction ( $P$ $<0.001$ ), fig 6 .

\section{Discussion}

The aggrecan concentrations as well as the aggrecan/COMP ratios decreased during progression of the destruction in the destructive group, which corroborates previous results from cross sectional studies. ${ }^{17}{ }^{18}$ Thus we find striking changes in the release of aggrecan during development of destruction, whereas the COMP levels seem to vary little. 
Table 2 Knee joint synovial fluid content of aggrecan, cartilage oligomeric matrix protein $(C O M P)$, and bone sialoprotein (BSP) in the first sample obtained from each patient. Values are median (range)

\begin{tabular}{|c|c|c|c|}
\hline & Destructive group ${ }^{\star}$ & Non-destrucctive group ${ }^{*}$ & $\begin{array}{l}\text { Differnce } \\
\text { (P value) }\end{array}$ \\
\hline Aggrecan (mg 1 $\left.{ }^{-1}\right)$ & $68.6(13.8$ to 198.1$)$ & $31.4(6.1$ to 91.4$)$ & 0.0005 \\
\hline $\operatorname{COMP}\left(\mathrm{mg}^{-1}\right)$ & $56.4(14.4$ to 84.6$)$ & $52.2(28.7$ to 115.0$)$ & $0.95, \mathrm{NS}$ \\
\hline $\begin{array}{l}\text { Aggrecan/COMP concentration } \\
\text { ratio }\end{array}$ & $1.12(0.47$ to 3.54$)$ & $0.58(0.12$ to 1.77$)$ & 0.00004 \\
\hline $\operatorname{BSP}\left(\mu \mathrm{g} 1^{-1}\right)$ & 355.2 (200 to 510.8$)$ & $310.1(72.0$ to 534.4$)$ & $0.33, \mathrm{NS}$ \\
\hline
\end{tabular}

ॠ Destructive group $n=18$, non-destructive group $n=25$.

This contrasts findings in a cross sectional study, where slightly, but significantly, lower concentrations of COMP were seen in patients with advanced destruction. ${ }^{19}$ The reasons for this discrepancy is at present unclear. The BSP concentrations in the destructive group increased during progression of destruction, which corroborates and extends the observations from our previous cross sectional study. ${ }^{22}$ It should be noted that the concentrations of BSP did not differ between the groups at initiation of the study and no clinical usefulness of BSP in predicting individual susceptibility is therefore apparent.

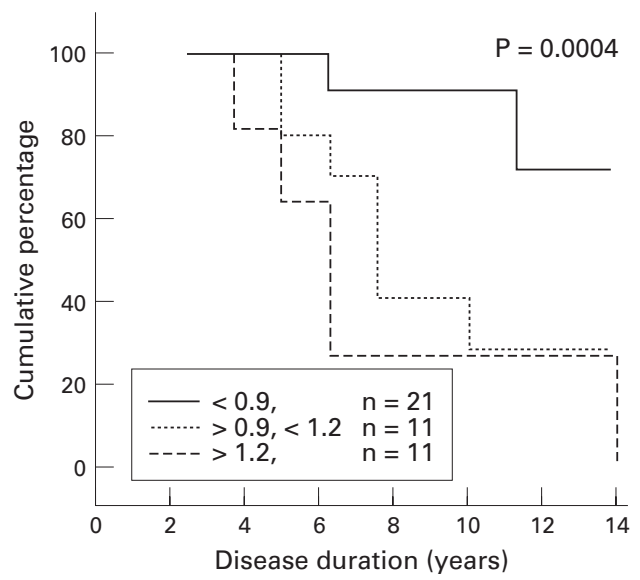

Figure 2 Life table analysis relating the synovial fluid aggrecan/COMP ratio in sample 1 for all patients $(n=43)$ to the cumulative percentage of hip/knee joint replacements. The lines denote ratios above the 75 th centile of all values $(>1.2)$, ratios between the 50th and the 75 th centile $(>0.9$ to $<1.2)$, and ratios below the 50th centile $(<0.9)$.

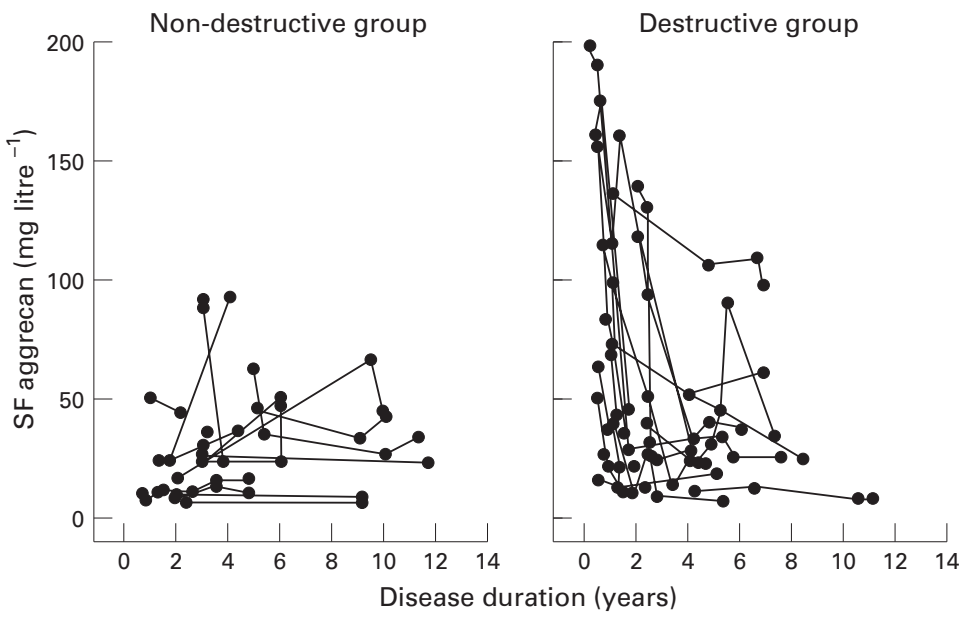

Figure 3 Synovial fluid concentrations of aggrecan in the two patient groups with rheumatoid arthritis. Serially collected samples were available from 16 knee joints in 12 patients in the non-destructive group and from 18 knee joints in 13 patients in the destructive group.
The longitudinal changes of the synovial fluid content of aggrecan is consistent with the view that already early in the disease process cartilage matrix turnover is disturbed, resulting in increased release of matrix components such as fragments of aggrecan. When the cartilage mass diminishes, the release of such fragments goes down. The lower aggrecan levels late in disease may also reflect a shift in the matrix turnover, with less "compensatory" matrix synthesis, with less release of newly formed aggrecan molecules, not incorporated in the matrix, but this remains to be proven. When a considerable reduction of the cartilage overlaying the bone has occurred, release of bone matrix macromolecules increases preferentially such components that are predominantly expressed in the cartilage-bone interphase, for example BSP. ${ }^{21}$ Thus release of BSP into synovial fluid is probably a sign of late, most probably irreversible, tissue damage.

A very conspicuous finding of this study is the high aggrecan concentrations and aggrecan/COMP ratios early in those patients who subsequently developed destruction necessitating hip or knee joint replacements. This finding is further emphasised by the life table analysis showing a clear cut relation between levels of aggrecan as well as of the aggrecan/COMP ratio in the first sample and the cumulative percentage of joint replacements. This is in line with our previous study of patients with long standing disease, but in the present study we additionally show that such a raised aggrecan concentration very early in disease is a potential marker of future progressive joint destruction. ${ }^{20}$ This increases the clinical usefulness of such measures. It is important to identify individuals prone to progressive destruction as early as possible in order to select patients for early, more aggressive treatment with the aim of preventing or lessening joint destruction. ${ }^{27}$ It should be pointed out that despite the clear cut statistical differences in aggrecan concentrations or aggrecan/ COMP ratios between the groups there is a considerable variability, especially within the destructive group. This underlines the importance of identifying several markers with somewhat different specificity for use in combination to increase the prognostic specificity.

It should be emphasised that the aggrecan/COMP ratio is a ratio of concentrations and should be considered as such, that is, it simply aims at defining a measure which can be used to overcome variations in the amounts of synovial fluid present in the joint, which may vary considerably between different aspirations. Thus in view of these findings the ratio between levels of two markers derived from the same tissue seems feasible in a clinical setting, regardless of the fact that the two markers may have different kinetics.

It is somewhat surprising that the synovial fluid findings of the knee joint predict the development of destruction in the hip joints - in fact the majority of the joint replacements were performed in hip joints. This may reflect the systemic nature of the disease. 


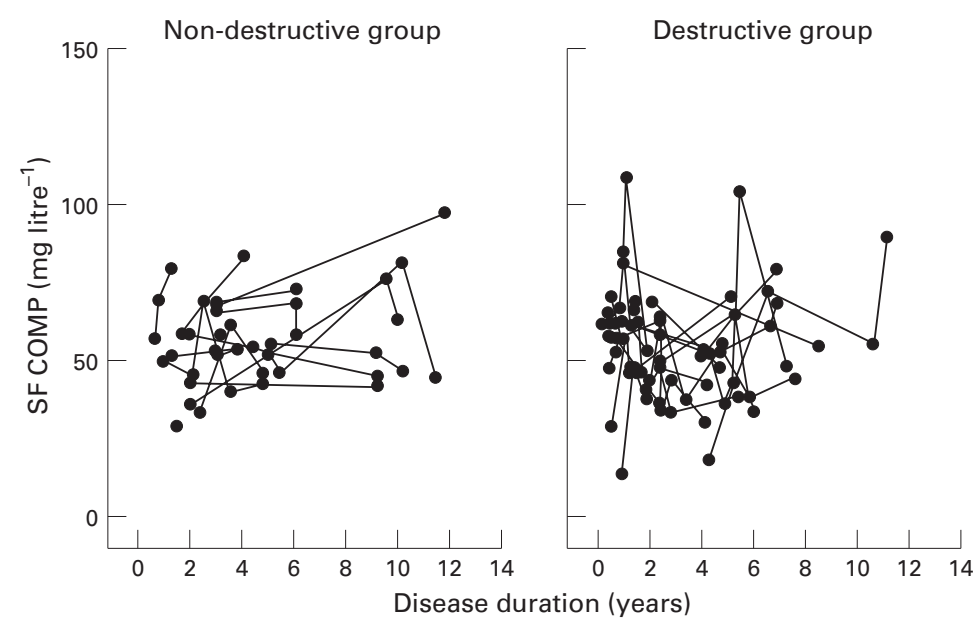

Figure 4 Synovial fluid concentrations of COMP in the two patient groups with rheumatoid arthritis. Serially collected samples were available from 16 knee joints in 12 patients in the non-destructive group and from 18 knee joints in 13 patients in the destructive group.

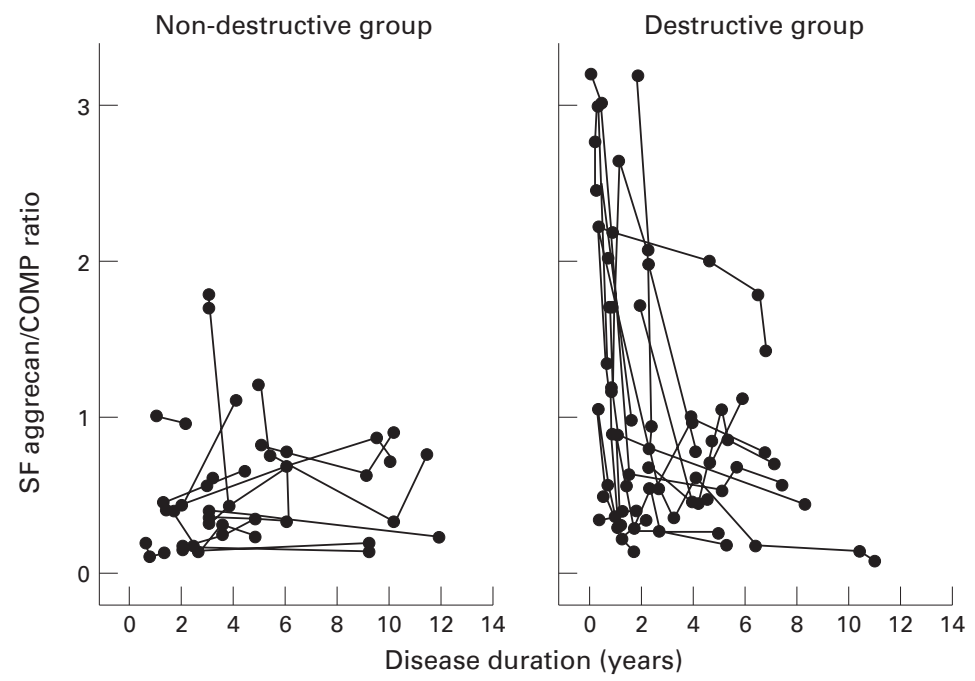

Figure 5 Synovial fluid aggrecan/COMP ratios in the two patient groups with rheumatoid arthritis.

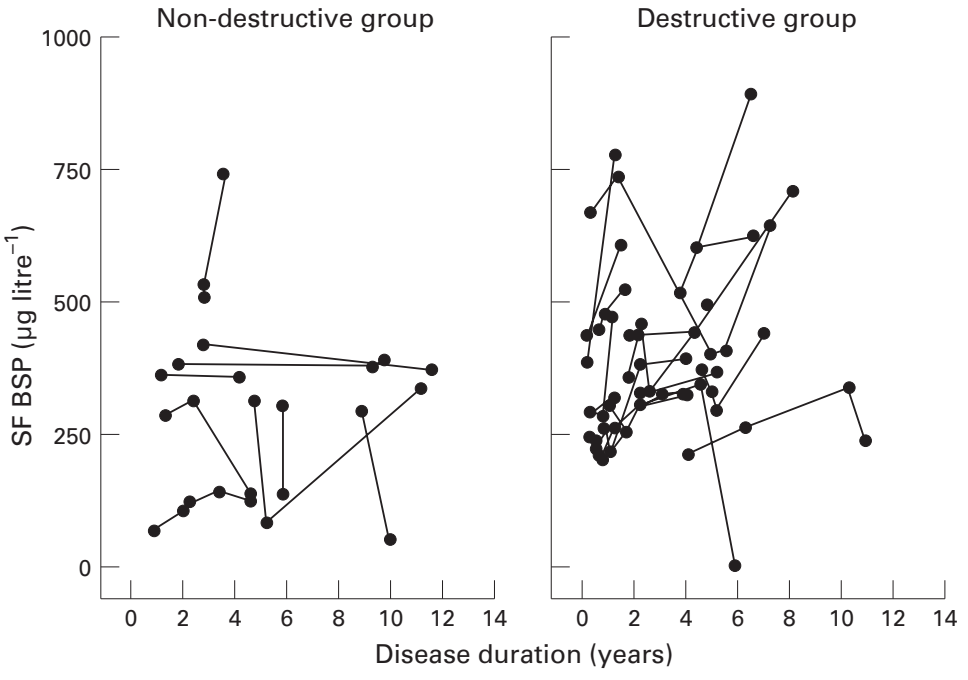

Figure 6 Synovial fluid concentrations of BSP in the two patient groups with rheumatoid arthritis. Serially collected samples were available from 10 knee joints in eight patients in the non-destructive group and from 17 knee joints in 12 patients in the destructive group.
Furthermore, it is possible that synovitis of the hip in rheumatoid arthritis is more common than hitherto recognised and coincides with knee joint synovitis more often than previously expected. ${ }^{27}$ In fact, five of the 14 patients who developed severe hip joint changes also had marked radiographic changes in their knee joints (Larsen grades 2-3). It may thus be hypothesised that hip involvement and knee involvement are related, but that the progression of changes varies with more rapid development of destruction in the hip joints. Whether findings in knee joint synovial fluid can also be used for predicting the development of destruction in other joints remains to be elucidated. It is worth noting that the patients in the destructive group tended to have more advanced changes in hands and feet, but there were usually no radiographs of these joints taken at the initiation of the study. Therefore no systematic study in this respect could be performed.

Given that the patient samples were recruited from a bank of fluids collected when the patients were seen because of a flare up of synovitis in the knee joint and not as part of a clinical study, it is not surprising that it was not possible to include all patients fulfilling the primary entry criteria. We have, however, no indications that the features of the patients whom we were not able to follow up differed from the included ones in such a way that their inclusion would have changed the results of the study.

It may be argued that we still do not know whether patients in the non-destructive group will eventually develop severe destructions in hips or knees, which could mean that the conclusions drawn would not be entirely true in a much longer perspective. The median follow up time after disease onset was in this group 9.0 years (range 6.8 to 13.4 years), which certainly excludes patients with rapidly progressive destruction of knees and hips. At the time of planning of the study no information was available from published reports detailing when in the course of the disease hip or knee replacements are most commonly performed. We therefore had to define this outcome criterion on the basis of our own clinical experience. However, it is very unlikely that patients who have normal radiographs and no symptoms after a disease duration of nine years will develop advanced destruction in these joints. In our previous study the median disease duration at study entry for all patients was 11 years. ${ }^{20}$ However, the five patients who developed knee joint damage leading to joint replacement at initiation of the study had a median disease duration of three years (range 0.5 to 5 ). These patients all received their knee arthroplasty between five and six years later. Thus, with the limitations mentioned, we feel confident that we have defined two patient groups with different outcome regarding development of knee or hip joint destruction from rheumatoid arthritis.

It does not seem likely that the synovial fluid concentrations of the cartilage markers would have been influenced differently by medication in the two groups. For sample 1, a detailed 
record of the treatment was obtained and showed no difference between the groups; for the other samples such a detailed examination was not possible, but there were no obvious differences between the groups in this respect.

In the present study we examined the longitudinal changes in synovial fluid concentrations of cartilage and bone markers. Such information may be useful in future trials of potentially tissue protective agents, where tissue derived macromolecules should be evaluated as markers for therapeutic effects on the tissue turnover.

We also focus on measurement of tissue specific macromolecules in synovial fluid for prognostic purposes and present promising data indicating that quantification of such markers should represent useful prognostic tools to forecast the development of large joint destruction in rheumatoid arthritis. In the future, several prognostic indicators dealing with different facets of rheumatoid arthritis should be employed to assess the prognosis in individual patients as accurately as possible. This requires validation of the different measures in large well characterised patient groups.

Supported by The Medical Faculty of Lund, The Swedish Medical Research Council, the Ax:son Johnson, Österlund, Kock, Nanna Svartz, Börje Dahlin, and Anna Greta Crafoord Foundations, the Förenade Liv Research Foundation, the King Gustaf V 80-year Fund, and Riksförbundet mot Reumatism. Skilful technical assistance by Mrs Mette Lindell is appreciated.

1 Harris ED. Rheumatoid arthritis. Pathophysiology and implications for therapy. N Engl J Med 1990;322:1277-89.

2 Panayi GS. The immunopathogenesis of rheumatoid arthritis. Rheumatol Rev 1992;1:63-74.

3 Klareskog L, Rönnelid J, Holm G. Immunopathogenesis and immunotherapy in rheumatoid arthritis: an area in transition. J Intern Med 1995;238:191-206.

4 Arend WP, Dayer J-M. Inhibition of the production and effects of interleukin- 1 and tumor necrosis factor $\alpha$ in effects of interleukin-1 and tumor necrosis factor $\alpha$ in
rheumatoid arthritis. Arthritis Rheum 1995;38:151-60.

5 Koopman WJ, Gay S. Do nonimmunologically mediated Koopman WJ, Gay S. Do nonimmunologically mediated pathways play a role in the pathogenesis of rheumato
arthritis? Rheum Dis Clin North Am 1993;19:107-22.

6 Fex E, Jonsson K, Johnson U, Eberhardt K. Development of radiographic damage during the first 5-6 years of rheumatoid arthritis. A prospective follow up study of a Swedish cohort. Br J Rheumatol 1996;35:1106-15.

7 Van Leeuwen MA, van der Heijde DMFM, van Rijswijk MH, Houtman PM, van Riel PLCM, van de Putte LBA, et al. Interrelationship of outcome measures and process variables in early rheumatoid arthritis. A comparison of radiologic damage, physical disability, joint counts, and acute phase reactants. J Rheumatol 1994;21:425-9.

8 Furst DE. Predictors of worsening clinical variables and outcomes in rheumatoid arthritis. Rheum Dis Clin North Am 1994;20:309-19.

9 Van Leeuwen MA, van Rijswijk MH. Acute phase proteins in the monitoring of inflammatory disorders. Baillieres Clin Rheumatol 1994;8:531-52.

10 Gough A, Faint J, Salmon M, Hassell A, Worsworth P, Pilling $\mathrm{D}$, et al. Genetic typing of patients with inflammatory arthritis at presentation can be used to predict outcome. Arthritis Rheum 1994;37:1166-70.

11 Heinegård D, Saxne T. Matrix proteins: potentials as body fluid markers of changes in the metabolism of cartilage
and bone in arthritis. J Rheumatol 1995;22(suppl 43): $71-4$

12 Poole AR, Dieppe P. Biological markers in rheumatoid arthritis. Semin Arthritis Rheum 1994;23(suppl (2):1731

13 Thonar EJ-MA, Shinmei M, Lohmander LS. Body fluid markers of cartilage changes in osteoarthritis. Rheum Dis Clin North Am 1993;19:635-57.

14 Peel N, Eastell R, Russel G. Markers of bone and collagen breakdown in early inflammatory arthritis. Baillieres Clin Rheumatol 1992;6:351-72.

15 Lohmander S, Saxne T, Heinegård D, eds. Molecular markers for joint and skeletal diseases. Acta Orthop Scand 1995;66(suppl 266)

16 Heinegård D, Oldberg Å. Glycosylated matrix proteins. In: Royce PM, Steinmann B, eds. Connective tissue and its heritable disorders. New York: Wiley-Liss, 1993:189-209.

17 Saxne $\mathrm{T}$, Heinegård $\mathrm{D}$, Wollheim FA, Pettersson $\mathrm{H}$. Differences in cartilage proteoglycan level in synovial fluid in early rheumatoid arthritis and reactive arthritis. Lancet 1985; ii: $127-8$.

18 Saxne T, Heinegård D. Synovial fluid analyses of two groups of proteoglycan epitopes distinguishes early and late cartiof proteoglycan epitopes distinguishes early and
lage lesions. Arthritis Rheum 1992;35:385-90.

19 Saxne T, Heinegård D. Cartilage oligomeric matrix protein. a novel marker of cartilage detectable in synovial fluid and blood. Br J Rheumatol 1992;31:583-91.

20 Saxne T, Wollheim FA, Pettersson H, Heinegård D. Proteoglycan concentration in synovial fluid:predictor of future cartilage destruction in rheumatoid arthritis. BMJ 1987;295:1447-8.

21 Hultenby K, Reinholt FP, Norgård M, Oldberg Å, Wendel $M$, Heinegård D. Distribution and synthesis of bone sialoprotein in metaphyseal bone of young rats show a distinctly different pattern from that of osteopontin. Eur J Cell Biol 1994;63:230-9.

22 Saxne T, Zunino L, Heinegård D. Increased release of bone sialoprotein into synovial fluid reflects tissue destruction in rheumatoid arthritis. Arthritis Rheum 1995;38:82-90.

23 Arnett FC, Edworthy SM, Bloch DA, McShane DJ, Fries JF, Cooper NS, et al. The American Rheumatism Association 1987 revised criteria for the classification of rheumatoid arthritis. Arthritis Rheum 1988;31:315-24.

24 Larsen A, Dale K, Eek M. Radiographic evaluation of rheumatoid arthritis and related conditions by standrad reference films. Acta Radiol Diagn 1977;18:481-91.

25 Saxne T, Heinegård D, Wollheim FA. Therapeutic effects on cartilage metabolism in arthritis as measured by release of proteoglycan structures into the synovial fluid. Ann Rheum Dis 1986;45:491-7.

26 Emery P, Salmon M. Early rheumatoid arthritis:time to aim for remission. Ann Rheum Dis 1995;54:944-7.

27 Eberhardt K, Fex E, Jonsson K, Geborek P. Hip involvement in early rheumatoid arthritis. Ann Rheum Dis 1995; $54: 45-8$ 